\title{
Research on the Teaching Mode of Oral Courses for Kindergarten Teachers based on OBE
}

\author{
Liqun $\mathrm{Wu}^{*}$ \\ West Yunnan, University Linchang, Yunnan 677000, China.
}

\begin{abstract}
The kindergarten teacher's spoken language course is the core course of the preschool education major. Its main purpose is to cultivate and improve the students' ability to comprehensively use the kindergarten teacher's oral language. This article is guided by the OBE concept, with the teaching goal of cultivating students' thinking ability as the main goal, and adopts the 5P mode in classroom teaching, namely preparation, proposition, panel discussion, and debate display (Performance) and perfection (Perfection), thereby improving the teaching quality of kindergarten teachers' oral courses.
\end{abstract}

Keywords: Outcomes-Based Education; Oral English of Kindergarten Teachers; Teaching Mode

Outcomes-based Education abbreviated as "OBE" means that the goal of instructional design and instructional implementation is the final learning achievement that students obtain through the education process. OBE emphasizes the following four questions: What are the learning outcomes we want students to achieve? Why do we want students to achieve such learning outcomes? How to effectively help students achieve these learning outcomes? How do we know that students have achieved these learning outcomes? The development of information technology and the information-based teaching model have put forward new requirements for the current curriculum reform. Based on the OBE concept, kindergarten teachersnow that students have achieved these learmodels.

"Kindergarten Teachers Spoken Language" is an applied subject that specifically explores the characteristics and rules of kindergarten teachers' oral language, and is a professional compulsory course for preschool education majors. Based on the OBE concept, the goal of the teaching design and teaching implementation of this course is that students complete the "pre-class learning tasks" assigned by the teacher in advance, and adopt the method of autonomous learning, which not only improves students' autonomous learning and oral expression skills, but also improves Studentsves g, whic (memory, comprehension, and application) abilities, as well as the use of group cooperative learning methods to form group learning results reports. With the support of teachers, students perform results display, mutual evaluation, self-evaluation and chiassesory, comprehension, an"post" homework expansion (combined with the suggestions in the class to develop a personal continuous improvement plan) not only improves the students' cooperation ability, but also improves their high-level (analysis, evaluation and creation) abilities. Based on the OBE concept, compared with the traditional model, the oral English curriculum for kindergarten teachers has the following innovations.

\section{Innovation of teaching concepts}

Adopt OBE (Education Based on Learning Outcomes) and the educational philosophy of flipped classrooms, and change the traditional teaching from "teacher-centered" to "student-centered". A hybrid teaching mode that combines the advantages of online teaching and traditional teaching is an "online" + "'offline" teaching. Through the organic combination of the two forms of teaching organization, learners' learning can be guided from shallow to deep to deep learning.

\section{Innovation of teaching objectives}

Oral English courses for kindergarten teachers are guided by the OBE concept. The traditional teaching focuses on cultivating students' low-level (memory, comprehension and application) abilities to focus on improving students' high-level (analysis, evaluation, and creation) abilities. The 5P model is adopted in classroom teaching, namely Preparation, Proposition, Panel discussion, Performance and Perfection. The goal of the specific teaching design and teaching implementation of this course is that students complete the "pre-class learning tasks" assigned by the teacher in advance, and adopt the method of autonomous learning, which not only improves students' autonomous learning and oral expression skills, but also promotes students' low-level abilities With the support of teachers, students will display the results, mutual evaluation and self-evaluation and udents will display theh not only(combined with the It is recommended to develop a personal continuous improvement plan), not only to improve studentsthe specific teaching design and teaching implementatilevel abilities.

\section{Innovation of teaching content}

Change the "single" textbook content to "diversified" teaching content. The teaching content keeps pace with the times and

Copyright (C) 2020 Liqun Wu

doi: $10.18282 / 1-e . v 9 i 4.1730$

This is an open-access article distributed under the terms of the Creative Commons Attribution Non-Commercial License (http://creativecommons.org/licenses/by-nc/4.0/), which permits unrestricted non-commercial use, distribution, and reproduction in any medium, provided the original work is properly cited. 
reflects the curriculum ideology. In this class, three questions from easy to difficult run through the entire teaching, that is, the "preclass" question: "How to use telling skills to design a story that young children like to listen to?", to the "in-class" guide "How to become a child Favorite teacher?tory that young children like tog about ecome a child Favorite teacher?tory that young children like to listen to curriculum ideology. In this class, three questions from easy to diffeaching implementation of this course is that students complete "Four Good Teachers" as their career goals. Teaching resources use the resources of Chaoxing Learning Link, the MOOC network platform of Chinese universities and the national quality curriculum resource library to expand the depth and breadth of student knowledge, and the teaching content keeps pace with the times, reflecting the document spirit of "Kindergarten Teacher Professional Standards (Trial)".

\section{Innovation of teaching means}

Change "single" teaching PPT to "multi-dimensional" teaching means. Using the "Super Star Learning" APP network platform, the MOOC network platform of Chinese universities and the national excellent course resource database to create multi-modal input and construct multi-dimensional classroom.

\section{Innovation of teaching methods}

Break through the "teacher-based teaching method" in traditional teaching as "student-based task-driven method, discussion method, practice method and reflection method". With the use of task-driven method, students are driven by a strong task motivation, through the active application of learning resources, to conduct independent exploration and interactive and collaborative learning. The innovative teaching method is mainly a hybrid teaching method: an "online" + "offline" teaching that combines the advantages of online teaching and traditional teaching. Through the organic combination of the two forms of teaching organization, learners' learning can be guided from shallow to deep to deep learning. The first is online learning: that is, "online teaching". Through the use of the "Superstar Learning Link" platform, teachers release relevant teaching videos and learning tasks before class, requesting the group to cooperate to complete the learning report, and upload the report to the "Superstar Learning Link". The platform requires each group to report the learning results of "independent inquiry" in class. The second is offline learning: "face-to-face teaching". Teachers conduct in-depth discussions on the problems raised by students, allow students to evaluate each other in groups, and teachers will make suggestions on difficult points, and conduct demonstrations and explanations, guide students to analyze problems, provide students with copying exercises, and give students opportunities to solve problems in practice. For example, at the end of the kindergarten teacher the end of the kinde problems in practice.ce.s and explanations, guide students to analyze problems, ups, and teachers will mg report, and upload the report to the .eaching content keeps p keeps pknowledge, and the $t$ "guide" in the growth of children.

\section{Innovation in the form of teaching organization}

The upper-level teaching organization is progressive, changing the traditional teaching organization form with "teachers" as the main body, and making "students" the main body of learning.

The teaching design adopts the OBE (result-based) teaching concept, that is, the goal of teaching design and teaching implementation is achieved by students by completing all the teaching tasks assigned by the teacher.

The first stage: Students receive and complete the "pre-class learning task" at "Study Tong" (group cooperation and use telling skills to design a story that young children like to listen to), and adopt independent learning methods, which not only improve students' independent learning and oral expression skills , But also improve students' low-level (memory, comprehension and application) abilities.

The second stage: the use of group cooperative learning to form group learning results report, with the support of teachers, students in the "class" display results, mutual evaluation and self-evaluation.

The third stage: "after class" homework expansion (combined with the suggestions in the class to develop a personal continuous improvement plan). After students complete all the learning tasks, they will not only improve their cooperation ability, but also improve their high-level (analysis, evaluation and creation) abilities.

\section{Innovation in Teaching Evaluation}

Change the traditional evaluation method with "teachers" as the main body, and let "students" become the main body of evaluation. After the group reports the group study report, conduct inter-group mutual evaluation and student self-evaluation.

After the first round of teaching reform, through analysis of the final exam results and questionnaire survey data, the results show that the key points of oral English courses for kindergarten teachers are prominent, students are generally able to carry out deep learning, teachersning and ora the teacher.nowledge, and the teaching content keeps p'ionnaire survey data, the results show that the key points of oral English courses for kindergarten teachers are prominent, students are generally able to carry out deep learning, teachestudents' high-level abilities, how teachers supervise and guide students to learn according to their own improvement plans, these are the directions for future exploration.

\section{References}

[1][America] Jonathan Bergman, Aaron Sams. Translated by Song Wei. Flipped Classroom and MOOC Teaching: An Educational Reform is Coming. [M] Beijing: Published by China Youth Publishing House, 2015.

[2]Zhang Wenjuan, Wang Lijun.Inquiry into the teacher's oral teaching model based on the flipped classroom concept.[J].Journal of Jiamusi Vocational Education College. 2016, (12): 387.

[3]Meng Jian. Research on the Teaching Model of "Child Teachers' Spoken Language" from the perspective of 4R theory [J]. Modernization of Education, 2018, 5(12): 193-195. 